\title{
Distribución factorial del ingreso y régimen de crecimiento en el Perú, 1942-2013
}

\author{
Germán Alarco Tosoni y César Castillo García ${ }^{1}$
}

\section{Resumen}

El documento se inicia con una revisión de la literatura sobre el vínculo entre la distribución factorial del ingreso y el crecimiento económico desde los economistas clásicos, con énfasis en los trabajos de Kalecki y los poskeynesianos que desarrollan el enfoque sobre regímenes de crecimiento. Se reconstruye y analiza la información estadística sobre la participación de los salarios, el ingreso de los independientes (o mixto) y las ganancias respecto del PIB del Perú entre 1942 y 2013, y se compara con los promedios de América Latina y otras economías. Además, se analiza la trayectoria de la participación salarial y el crecimiento desde una perspectiva comparada, y se aplica un modelo de ecuaciones simultáneas estimado a través de mínimos cuadrados en tres etapas (MC3E) y del método generalizado de momentos (MGM) para determinar el régimen de crecimiento. Se concluye que este se encuentra basado en salarios. Las políticas distributivas a favor de este componente serían positivas para el nivel de actividad económica.

\section{Palabras clave}

Distribución del ingreso, crecimiento económico, medición, ingresos, salarios, producto interno bruto, Perú

\section{Clasificación JEL}

E12, E25, F43, J30, O54

\section{Autores}

Germán Alarco Tosoni es Profesor investigador de Pacífico Business School, de la Universidad del Pacífico, Perú. Correo electrónico: g.alarcotosoni@up.edu.pe.

César Castillo García es Asistente de investigación de Pacífico Business School, de la Universidad del Pacífico, Perú. Correo electrónico: c.castillog@up.edu.pe. 


\section{Introducción}

El tema de la distribución del ingreso está nuevamente en la agenda internacional y ya no es solo un asunto que preocupe a los economistas clásicos, la escuela regulacionista, los poskeynesianos y los marxistas. Su importancia se pone de relieve incluso en recientes estudios del Fondo Monetario Internacional (FMI) y de otros organismos financieros internacionales. Una excesiva desigualdad afecta negativamente la demanda y el nivel de actividad económica (Kumhof y Rancière, 2010; Ostry, Berg y Tsangarides, 2014; Cingano, 2014; Lakner y Milanovic, 2015), el orden social (Figueroa, 2010; Stiglitz, 2015) y el sistema democrático (Piketty, 2014; Oxfam, 2014).

Si bien en las últimas décadas se puso mucho énfasis en reorientar los estudios hacia la distribución personal del ingreso, en los años más recientes han surgido otros análisis que inciden en la distribución factorial, aunque la lista de estos trabajos para las economías latinoamericanas aún es reducida: Abeles, Amarante y Vega (2014); Alarco (2014); OIT (2012); CEPAL/OIT (2012); Neira (2010); Lindenboim (2008); Frankema (2009); Bértola y otros (2008), y Fitzgerald (2009), entre otros. En la mayoría de estas investigaciones todavía subsiste el problema de que los ingresos de los independientes o mixtos se ubican dentro del excedente bruto de explotación.

La presente investigación tiene dos objetivos centrales. En primer lugar, se plantea la reconstrucción de las series largas para los diferentes componentes de la distribución factorial del ingreso en el Perú: remuneraciones, ingresos de los independientes y ganancias. Mientras que los trabajos anteriores comprendieron el período 1950-2012, este iría de 1942 a 2013. Por otra parte, se distinguiría de las series del excedente bruto de explotación el componente relativo a las ganancias y los ingresos mixtos. En segundo término, en la línea de los trabajos poskeynesianos y regulacionistas, se trataría de dilucidar si el aumento de la participación de la masa salarial y de los ingresos mixtos en el producto contribuye - o no - a que se eleve el nivel de actividad económica. En el primer caso sería un régimen de crecimiento económico basado en salarios y en el segundo se trataría de un régimen basado en ganancias. Se supone que los ingresos mixtos (principalmente de los campesinos y los trabajadores informales urbanos) se pueden agrupar con los asalariados en lugar de compartir espacios con los perceptores de ganancias.

La hipótesis principal es que la participación salarial en el producto ha tenido una evolución descendente a partir de los años ochenta. En el segundo caso, los resultados relativos al régimen de crecimiento son útiles para definir cuál debe ser el énfasis distributivo de las políticas públicas que permitirían, de conformidad con la evidencia histórica, coadyuvar a que la economía siga creciendo. Desde Kalecki (1956), la distribución factorial del ingreso es un elemento central para explicar de manera explícita el nivel y la evolución del PIB. A partir de Boyer (1988a y 1988b) y Bhaduri y Marglin (1990) se ha profundizado la perspectiva de los regímenes de crecimiento que analizan los diversos canales de transmisión de la participación de los salarios sobre el consumo privado, la inversión privada, las exportaciones y la productividad.

El presente documento tiene cuatro secciones, más la introducción y las conclusiones. En la sección II se presenta la literatura que vincula la distribución del ingreso con los regímenes de crecimiento. En la sección III se muestran las series estadísticas de los diferentes componentes del ingreso y se presentan los resultados básicos de la evolución de la participación de la masa salarial, del ingreso de los independientes y las ganancias respecto del PIB, algunos factores explicativos de estos y el análisis de los resultados del Perú respecto de América Latina, los Estados Unidos y el Reino Unido. En la sección IV se detalla la relación entre la participación salarial y el crecimiento económico del Perú, comparada con la de América Latina. Por último, en la sección V se describe el modelo de ecuaciones simultáneas seleccionado para determinar el régimen de crecimiento económico del Perú para el período analizado, y se presentan y analizan los resultados obtenidos. 
Entre los alcances del estudio se debe destacar su perspectiva macroeconómica, con la omisión de factores de carácter estructural y sociopolítico. No se analizan las vinculaciones entre la distribución factorial y la distribución personal del ingreso, ni se consideran las influencias de los fenómenos tecnológicos y de la financierización sobre la distribución del ingreso. Tampoco se incorporan recomendaciones de política para mejorar la distribución del ingreso y el crecimiento económico, entre otros elementos.

\section{Distribución y regímenes de crecimiento económico}

La vinculación de las variables distributivas con el crecimiento económico es un tema añejo. Es transparente en el flujo económico de Quesnay (1980). Smith (2010) manifiesta un interés por la mejora de las condiciones de vida de la población y en particular de los salarios de los trabajadores que contribuyen y deben beneficiarse del crecimiento económico. Para Ricardo (1973), el crecimiento económico es obra esencialmente de los capitalistas, que son la clase responsable de la acumulación de capital. Marshall (1957), por su parte, no va a superar la paradoja que eliminó toda la problemática distributiva en la escuela neoclásica. Si bien reconoce que el aumento del nivel de vida del conjunto de la población elevaría tanto la eficiencia como el bienestar nacional, también considera que puede afectarlo. A partir de él se rompe todo vínculo entre la participación salarial y el nivel de actividad económica.

El vínculo entre la participación salarial y el crecimiento económico reaparece con Keynes (1943), aunque de manera implícita, a través de la propensión a consumir y el multiplicador del gasto, y se vuelve más evidente cuando se establecen las recomendaciones generales de política económica². Los salarios son el componente principal del ingreso y el determinante de la propensión a consumir, y este, a su vez, del multiplicador del gasto. En el capítulo 24 de la Teoría general del empleo, el interés y el dinero, esto se profundiza cuando se plantea la posibilidad de establecer impuestos a los ingresos y las herencias, que tendrían el propósito de aumentar la propensión a consumir de la comunidad ${ }^{3}$.

Kalecki (1956) determina explícitamente la distribución del ingreso, en particular de la masa salarial respecto del ingreso, a partir del proceso de fijación de los precios determinados por la oferta, y posteriormente vinculada a la determinación del nivel de demanda y producción. En la primera fase, la participación de los salarios en el ingreso depende del grado de monopolio de la rama industrial en concreto, de la relación entre salarios y materias primas en dicha actividad (relación técnica) y de la estructura industrial. De esta forma, la participación de los salarios en el ingreso o producto depende inversamente de elementos como la diferenciación de productos (desarrollo de la promoción de ventas por medio de la publicidad), la existencia de procesos de concentración y la presencia de acuerdos tácitos o cárteles, y de manera directa de la fuerza de los sindicatos y de otra variable relativa a la influencia que sobre el grado de monopolio tienen las variaciones de los gastos generales respecto de los costos primos.

Kalecki también determina el nivel de la demanda y de la actividad económica a partir de los factores explicativos de las ganancias, que se derivan de aplicar el principio de demanda efectiva por grupo social: los capitalistas ganan lo que gastan, mientras que los asalariados gastan lo que ganan. De esta forma, las ganancias brutas estarían determinadas por los niveles de consumo (dependientes del nivel de las ganancias) y de inversión, el excedente de exportaciones (exportaciones menos

\footnotetext{
2 Esto es evidenciado por Kaldor (1955).

3 Los impuestos a los ingresos y las herencias redistribuirían ingresos de los estratos ricos a los pobres, elevando la propensión media a consumir de la sociedad y aumentando el multiplicador del gasto.
} 
importaciones) y el déficit presupuestal ${ }^{4}$. Posteriormente, asumiendo que la masa salarial depende del nivel de producto, el producto depende de las ganancias afectadas por un multiplicador que toma en cuenta la participación de la masa salarial en el producto. En síntesis, cuando aumenta la inversión privada, el excedente de exportaciones y el déficit presupuestal, se incrementa el producto, dependiendo de los multiplicadores asociados a la propensión a consumir de los capitalistas y de la participación de la masa salarial en el producto. En la medida en que estos aumenten, el producto crecerá más, mientras que si disminuyen el crecimiento del producto será menor.

La discusión sobre los regímenes de crecimiento reapareció en la agenda económica a partir de la escuela francesa de la Teoría de la Regulación. Al respecto, Bowles y Boyer (1988) trabajaron sobre el argumento de que el nivel de empleo puede responder de manera positiva o negativa al nivel de salario real, lo que denominan como régimen de empleo basado en salarios o en ganancias, respectivamente. Bhaduri (2007) y Bhaduri y Marglin (1990), desde la visión poskeynesiana, proporcionaron una parte importante del marco teórico que sirvió de base para la evaluación de los regímenes de crecimiento. Su objetivo fue desarrollar un marco macroeconómico para analizar la relación entre salarios y desempleo, evaluando las dos perspectivas básicas en relación con el salario real: como costo de producción (vertiente neoclásica) o como poder de compra de los trabajadores que estimula la demanda. Stockhammer (2011) establece que la determinación del régimen de crecimiento económico dominante (basado en salarios o en ganancias) resulta de evaluar los efectos de los cambios de la participación salarial en la demanda y la oferta. En el caso de la demanda, es probable que los gastos de consumo tengan una relación directa con la participación salarial. Por lo general, los salarios reales más altos se traducirán en un nivel más elevado de gastos de consumo porque los asalariados tienen una propensión a consumir más alta que los perceptores de ganancias. En segundo término, existe la posibilidad de que la inversión reaccione de manera negativa ante un aumento en la participación salarial (por un descenso en la participación de las ganancias o de los márgenes de ganancia de las empresas). En tercer lugar, cabe la posibilidad de que las exportaciones netas tengan una reacción negativa ante los aumentos en la participación salarial porque, según una tasa de cambio específica, la rentabilidad disminuye o las exportaciones se vuelven menos competitivas. Estos efectos, no obstante, dependerán del grado de apertura y del tipo de productos que se exporten e importen.

Al respecto, no se puede conocer ex ante cuál será el efecto neto, pero este dependerá de los resultados parciales. Si el efecto por el lado del consumo es mayor que los de las exportaciones netas y las inversiones, el resultado total es positivo y la economía se encuentra en un régimen de demanda basado en los salarios. Por el contrario, si las inversiones y las exportaciones netas reaccionan con más fuerza, el efecto total de un aumento de la participación salarial en la demanda es negativo y el régimen de demanda estará basado en las ganancias. Con relación a la oferta, la cuestión clave es cómo inciden los cambios en la participación salarial o en los salarios reales en el crecimiento de la productividad (progreso tecnológico, en una versión más amplia). La contribución puede ser positiva, en el marco de la teoría de Kaldor-Veerdoorn, indistinta o negativa, en el caso de los economistas ortodoxos.

Los estudios empíricos sobre los regímenes de crecimiento son numerosos. Stockhammer y Ederer (2007) señalan que existen dos vertientes. En el primer grupo se trata de evaluar el tema a partir de estimar un modelo VAR (modelo de autorregresión vectorial) estructural. La ventaja de esta aproximación es que se incorporan las interacciones entre las diferentes variables y la desventaja es que eso dificulta la identificación de los efectos de las variables individuales. En el segundo grupo de estudios se estiman ecuaciones de consumo, inversión y exportaciones netas en términos de formas

\footnotetext{
4 Esto en la medida en que el sector privado de la economía recibe más en forma de gastos gubernamentales de lo que paga en impuestos. Asimismo, en rigor a las ganancias brutas, habría que deducir el ahorro bruto de los capitalistas y de los trabajadores.
} 
reducidas, sin considerar los últimos avances de la econometría e ignorando la problemática de las raíces unitarias. Por lo tanto, no se tiende a aplicar modelos de corrección de errores. Los modelos estimados tienden a limitarse a los modelos teóricos especificados. Posteriormente, se profundizó en la econometría, ampliando las variables de control e incorporando otros temas, como la evaluación de los efectos de la globalización y la financierización.

En la primera vertiente, Stockhammer y Onaran (2004) analizan la relación entre demanda efectiva, distribución del ingreso y desempleo en los Estados Unidos, Francia y el Reino Unido utilizando un modelo VAR estructural, siguiendo la tradición de Kalecki y Kaldor. El segundo grupo de modelos se focalizó en estimar los efectos de las variaciones en los salarios reales o las participaciones de los sueldos y salarios en el PIB sobre el consumo privado, la inversión privada y las exportaciones netas. Entre estos estudios se destaca el de Naastepad y Storm (2007), quienes evaluaron el régimen de demanda en las principales economías de la Organización de Cooperación y Desarrollo Económicos (OCDE) para el período 1960-2000. Stockhammer y Ederer (2007) analizaron el caso de Austria. Posteriormente, Stockhammer, Onaran y Ederer (2009) elaboraron una investigación sobre 12 economías europeas con resultados diversos.

Al analizar el caso específico de Alemania, Stockhammer, Hein y Grafl (2011) encuentran que la declinación de la participación salarial sobre la demanda interna es típicamente contractiva, mientras que las exportaciones netas son expansivas en función del grado de apertura de la economía. De esta forma, la globalización puede transformar el régimen basado en salarios en otro basado en ganancias, por lo que se requiere de un análisis pormenorizado. Onaran, Stockhammer y Grafl (2009 y 2011) incorporan al debate y análisis empírico la problemática de la financierización en una economía abierta analizando el caso de los Estados Unidos. Onaran y Galanis (2012) realizaron una evaluación de las economías del Grupo de los Veinte (G-20) (incluidas la Argentina, el Canadá, China, la India, México, la República de Corea, Sudáfrica y Turquía) y obtuvieron algunos resultados interesantes (OIT (2011) presenta una síntesis sobre el tema). Alarco (2016), utilizando el modelo de Naastepad y Storm (2007), determinó el régimen de crecimiento económico para 16 economías latinoamericanas mediante el método de mínimos cuadrados ordinarios para el período 1950-2012. La Argentina, el Brasil, Colombia, Costa Rica, el Ecuador, El Salvador, México, el Paraguay, el Perú, el Uruguay y Venezuela (República Bolivariana de) tendrían un régimen de crecimiento basado en salarios, en tanto que Bolivia (Estado Plurinacional de), Chile, Honduras, Nicaragua y Panamá estarían bajo un régimen basado en ganancias.

En cuanto a las críticas al enfoque de regímenes de crecimiento, Nikiforos (2014) plantea que una economía no puede ser permanentemente dirigida por las ganancias o por los salarios. Palley (2014) señala que no es posible clasificar una economía en un régimen de crecimiento económico u otro, ya que esto depende de las políticas que se apliquen. Asimismo, la econometría utilizada para tipificar el régimen de crecimiento puede cambiar con las modificaciones en la política económica: cambios en la estructura de la propiedad, políticas tributarias y financierización y otros. El autor plantea varios casos en los que el régimen de crecimiento puede basarse en salarios o en ganancias cuando en realidad los resultados son al revés. Asimismo, el enfoque puede ser excesivamente determinista al establecer ex ante las políticas que se asocian a cada régimen de crecimiento económico.

\section{Estadística básica, algunos factores explicativos y análisis comparativo}

Las series de la distribución factorial del ingreso se reconstruyeron a partir de la información oficial del Banco Central de Reserva del Perú (BCRP), el Instituto Nacional de Estadística e Informática (INEI) y 
el Ministerio de Hacienda y Comercio entre 1942 y 2013. Para la reconstrucción del PIB nominal y de sus componentes por el lado del ingreso (participación de los impuestos y subsidios a la producción y participación del consumo de capital fijo) se utilizó la fórmula proporcionada por Pedagua (2009). En el caso del ingreso de los independientes se tuvo que reconstruir el ingreso mixto agrícola y no agrícola a partir de las fuentes anteriores y del índice de producción de Seminario (2015). En el caso del componente no agrícola también se utilizó la información de García (2013). Las ganancias se obtuvieron residualmente. El detalle completo de la metodología considerada se presenta en Castillo (2015).

En los gráficos 1 y 2 se muestran los datos observados y la tendencia no lineal aplicando el filtro de Hodrick-Prescott de la masa salarial, los ingresos de los independientes y las ganancias respecto del PIB. En el caso de la participación salarial, el punto máximo se observa en los años sesenta, con una reducción en las décadas de 1970 y 1980 y hasta el primer quinquenio de los años noventa. A partir del segundo quinquenio de los años noventa se registra una recuperación, aunque con una ligera contracción en los últimos años de la serie estadística. Asimismo, en el caso de la participación de los ingresos de los independientes en el PIB la tendencia es claramente descendente con un ligero crecimiento en los años ochenta y noventa. Por otra parte, la tendencia de las ganancias es ascendente, pero cíclica, con mayores participaciones en los años cincuenta y setenta y desde el segundo quinquenio de la década de 1990 hasta la fecha.

Gráfico 1

Perú: participación salarial e ingreso de independientes en el PIB, 1942-2013 (En porcentajes)

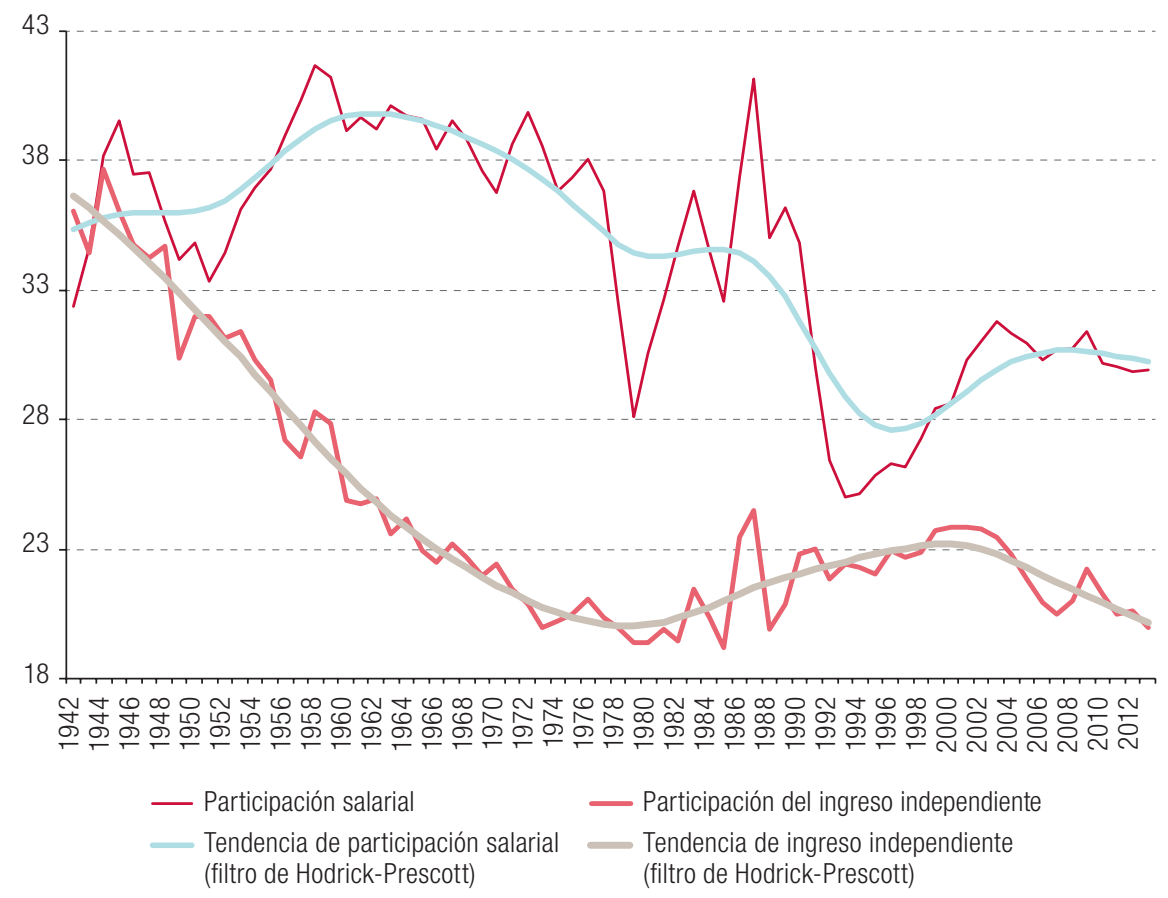

Fuente: Elaboración propia, sobre la base de Banco Central de Reserva del Perú (BCRP); Instituto Nacional de Estadística e Informática (INEI); y N. García, "Fast economic growth and income distribution (Peru 1990-2010)", Economie Appliquée, № 1, 2013 [en línea] http://www.itf.org.ar/pdf/documentos/89_2013.pdf. 
Gráfico 2

Perú: participación de las ganancias en el PIB, 1942-2013

(En porcentajes)

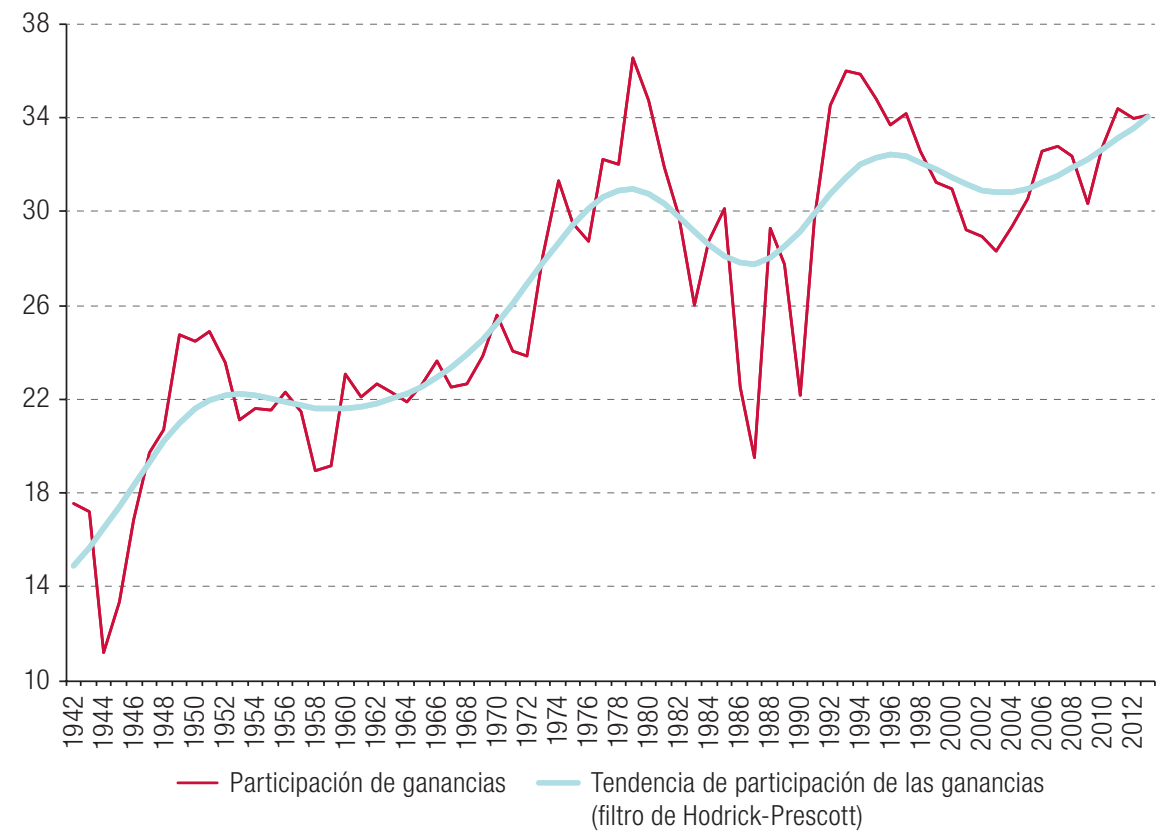

Fuente: Elaboración propia, sobre la base de Banco Central de Reserva del Perú (BCRP); Instituto Nacional de Estadística e Informática (INEI); y N. García, "Fast economic growth and income distribution (Peru 1990-2010)", Economie Appliquée, № 1, 2013 [en línea] http://www.itf.org.ar/pdf/documentos/89_2013.pdf.

Para explicar la evolución de los gráficos 1 y 2 hay que considerar factores estructurales internos e internacionales, elementos sociopolíticos e institucionales, eventos externos, elementos técnicos, resultados de la política económica y otros temas coyunturales. No es una cuestión simple. Para empezar, la mayor participación de los salarios en el PIB durante la década de 1960 responde al estilo de crecimiento fordista, que era la práctica a nivel internacional y local de esos tiempos. Se trataba de mantener un balance entre los beneficios y los salarios. Esta es la etapa de la migración a las ciudades, la urbanización, la mejora de los sistemas de seguridad social y de las condiciones laborales, y el crecimiento de la clase media. Asimismo, en el caso peruano, la primera pérdida de participación de los salarios se produce después de los primeros ajustes macroeconómicos y el deterioro de los términos de intercambio en la década de 1970, entre la primera y la segunda fase del gobierno militar. La siguiente caída notoria de la participación salarial se registra en la última parte de la década de 1980, cuando confluyen los ajustes macroeconómicos que postergaron los efectos de la crisis de la deuda de América Latina en el Perú, los severos desbalances macroeconómicos fiscales y monetarios incubados en 1987 y gran parte de 1988, los efectos del terrorismo y el deterioro de la situación económica internacional. El mayor descenso de la participación salarial se produce con las políticas de ajuste y estabilización del gobierno de Fujimori en julio de 1990, cuya secuela dura todo ese quinquenio. De ahí en adelante mejora la participación salarial hasta el auge de los precios de las materias primas (en especial los productos mineros), que elevan el peso de las ganancias en el PIB y reducen la cuota correspondiente a los salarios.

El proceso de migración y urbanización, el crecimiento de los sectores secundarios y el deterioro de los términos de intercambio en contra del agro impulsan la drástica caída del ingreso de los independientes, principalmente del campo. Sin embargo, al tiempo que cae el peso de los salarios en el PIB durante la década de 1990, la participación de los independientes urbanos (micropropietarios y economía informal) aumenta su cuota en el PIB para perderla ligeramente en los últimos años. Por 
otra parte, la participación de las ganancias en el producto tiene una tendencia ascendente, con ciclos que parecen asociarse a la mejora y el deterioro de los términos de intercambio externo y a la mayor participación del sector extractivo (minero y de hidrocarburos) a fines de la década de 1940, en el segundo quinquenio de los años setenta y a partir del último auge exportador que parece culminar en 2012.

La explicación anterior, de carácter más estructural, sobre las tendencias y fluctuaciones de las participaciones de los salarios, del ingreso de los independientes y de las ganancias respecto del PIB puede ir acompañada de otras variables económicas más instrumentales: inflación, términos de intercambio externos, evolución de las tasas de interés, remuneración mínima vital real y precios del petróleo. Sin embargo, no es posible obtener una sola función explicativa de las diferentes participaciones de los componentes de la distribución factorial del ingreso, ya que las series estadísticas que podrían servir como variables explicativas no tienen la misma periodicidad, o se trata de estadísticas entrecortadas, como la relativa a los precios al productor agropecuario, que resulta útil para explicar el componente agrícola de los ingresos de los independientes. Asimismo, cuando se incorporan conjuntamente las diversas variables exógenas, se producen problemas de autocorrelación y otros fallos econométricos. En el cuadro 1 se presentan algunas funciones explicativas de la participación de la masa salarial en el PIB, donde se destacan los efectos de la inflación, los términos de intercambio externos, la tasa de interés activa nominal, la remuneración mínima vital real y los precios del petróleo.

Cuadro 1

Algunas regresiones explicativas de la participación de la masa salarial en el PIB

\begin{tabular}{|c|c|c|c|c|c|}
\hline Ecuación (variable dependiente W/PBI) & Ecuación 1 & Ecuación 2 & Ecuación 3 & Ecuación 4 & Ecuación 5 \\
\hline c & $\begin{array}{c}0,356494 \\
(80,1382)^{\star}\end{array}$ & $\begin{array}{c}0,259283 \\
(9,3968)^{*}\end{array}$ & $\begin{array}{r}0,349882 \\
(13,1080)^{*}\end{array}$ & $\begin{array}{c}0,276359 \\
(14,2438)^{*}\end{array}$ & $\begin{array}{r}0,318823 \\
(42,4157)^{*}\end{array}$ \\
\hline Inflación & $\begin{array}{c}0,001294 \\
(2,8833)^{\star}\end{array}$ & $\begin{array}{l}0,000455 \\
(2,0963)^{*}\end{array}$ & & $\begin{array}{l}0,000533 \\
(0,4095)\end{array}$ & $\begin{array}{c}0,005212 \\
(2,4207)^{*}\end{array}$ \\
\hline Tasa de interés activa nominal & & & & $\begin{array}{l}0,001171 \\
(0,5410)\end{array}$ & $\begin{array}{l}-0,006496 \\
(-1,8402)\end{array}$ \\
\hline Remuneración mínima vital real & & $\begin{array}{l}0,0000685 \\
(4,2049)^{*}\end{array}$ & & $\begin{array}{l}0,000157 \\
(6,1852)^{*}\end{array}$ & \\
\hline $\begin{array}{l}\text { Términos de intercambio } \\
\text { externos (1954=100) }\end{array}$ & & $\begin{array}{l}-0,000504 \\
(-3,4566)^{*}\end{array}$ & & $\begin{array}{l}-0,000367 \\
(-2,9873)^{*}\end{array}$ & \\
\hline Precio del petróleo Brent nominal & & & $\begin{array}{l}-0,0004 \\
(-1,4995)\end{array}$ & & \\
\hline Variable ficticia $(1979,1989-2000)$ & $\begin{array}{l}-0,084574 \\
(-7,5886)^{*}\end{array}$ & & & & $\begin{array}{l}-0,040128 \\
(-3,4666)^{\star}\end{array}$ \\
\hline Variable ficticia (1990-2000) & & & & $\begin{array}{l}-0,028254 \\
(-2,6915)^{*}\end{array}$ & \\
\hline$A R(1)$ & & $\begin{array}{l}0,805101 \\
(8,8849)^{*}\end{array}$ & $\begin{array}{c}0,903094 \\
(15,9866)^{*}\end{array}$ & & \\
\hline $\mathrm{R}^{2}$ & 0,45528 & 0,880755 & 0,849168 & 0,866923 & 0,479054 \\
\hline $\mathrm{F}$ & 28,83525 & 83,09322 & 168,8968 & 27,36059 & 7,356676 \\
\hline DW & 0,507641 & 1,712992 & 1,589216 & 1,880992 & 0,675966 \\
\hline Período & $1942-2013$ & $1962-2012$ & $1950-2013$ & 1986-2013 & $1986-2013$ \\
\hline
\end{tabular}

Fuente: Elaboración propia, sobre la base de Banco Central de Reserva del Perú (BCRP); Instituto Nacional de Estadística e Informática (INEI); Fondo Monetario Internacional (FMI); y B. Seminario, El desarrollo de la economía peruana en la era moderna. Precios, población, demanda y producción desde 1700, Lima, Universidad del Pacífico, 2015.

Nota: Debajo del valor de los parámetros se anota el $t$ estadístico y el asterisco indica que este es significativamente diferente de cero al 95\% de confianza.

Para todo el período 1942-2013, la inflación es una variable explicativa relevante de la evolución de la participación de la masa salarial en el PIB. Sin embargo, tanto cuando se producen períodos de alta inflación e hiperinflación, como cuando hay una política manifiesta de frenar los ajustes salariales (principalmente cuando se aplican políticas de ajuste o estabilización), asume una relación 
negativa que explicaría el $45 \%$ de las observaciones. Si a la función explicativa anterior se le agrega la remuneración mínima vital real, se observa una contribución positiva a la participación salarial. En esa misma ecuación, la mejora de los términos de intercambio externos reduce la participación salarial en la medida en que las ganancias son mayores como resultado de que los precios de exportación de los productos primarios son más elevados. Las ganancias de los sectores extractivos tienen un impacto positivo en las ganancias de toda la economía, lo que afecta negativamente la participación salarial en el PIB. Asimismo, tanto la elevación de los precios del petróleo como el incremento de las tasas de interés activas reducen la participación salarial en el producto.

En el gráfico 3 se muestran los resultados de comparar la participación de la masa salarial del Perú con la participación de la misma variable de América Latina (Alarco, 2014), con y sin el Perú 5 . Al respecto, destacan los mayores niveles en la participación de las remuneraciones de la serie latinoamericana respecto de la peruana, lo que da cuenta de niveles más elevados de asalarización. Asimismo, después de alcanzar un punto máximo en los años sesenta, la tendencia es descendente, aunque con una caída más pronunciada en el caso peruano a partir de mediados de la década de 1970 (crisis entre 1975 y 1978), mientras que en la región hay una ligera caída previa a la crisis de los años ochenta para continuar con una sima a finales del primer quinquenio del siglo XXI. La alta inflación e hiperinflación registrada en el Perú entre 1986 y 1990 y el programa de ajuste del período 1990-1994 generan un brusco descenso de la participación salarial en el Perú, a diferencia de lo que ocurre en la región. A partir del segundo quinquenio del siglo XXI, mientras la participación salarial del Perú baja, la regional aumenta, sobre todo por el impulso a los salarios y el mercado interno en la Argentina y el Brasil.

\section{Gráfico 3}

Perú y América Latina: tendencia de la participación salarial en el PIB (En porcentajes del PIB)

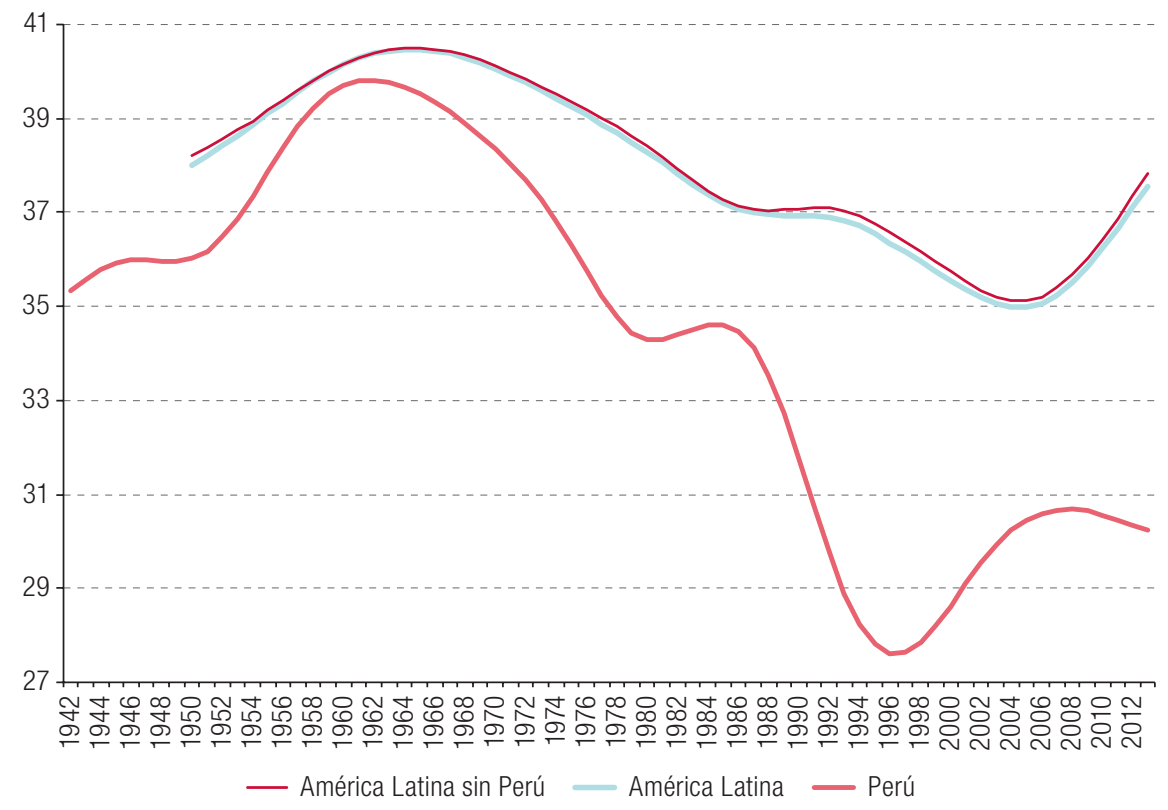

Fuente: Elaboración propia, sobre la base de Banco Central de Reserva del Perú (BCRP); Instituto Nacional de Estadística e Informática (INEI); Comisión Económica para América Latina y el Caribe (CEPAL), "Estadísticas e indicadores", 2013 [en línea] http://estadisticas.cepal.org/cepalstat/WEB_CEPALSTAT/estadisticasIndicadores.asp?idioma=e; Banco Mundial, "World Development Indicators", 2014 [en línea] http://databank.worldbank.org/ddp/home.do?Step=1\&id=4); y G. Alarco, "Participación salarial y crecimiento económico en América Latina 1950-2013", Revista CEPAL, № 113 (LC/G.2614-P), Santiago, Comisión Económica para América Latina y el Caribe (CEPAL), 2014.

\footnotetext{
${ }^{5}$ Las tres series se presentan como tendencias no lineales a partir de la aplicación del filtro de Hodrick-Prescott sobre los datos observados.
} 
En el gráfico 4 se muestran los resultados de la comparación de la participación de la masa salarial en el PIB del Perú (con escala en el eje del lado izquierdo) con las participaciones de los Estados Unidos y el Reino Unido (con escala en el eje del lado derecho), como ejemplos de dos economías desarrolladas relevantes con series estadísticas comparables. Estas series también están corregidas por el filtro de Hodrick-Prescott. La primera diferencia notoria es la escala donde la información de los Estados Unidos y el Reino Unido (que también incluyen otras compensaciones como apoyo a fondos de pensiones, salud y seguros) es claramente superior a la del Perú. Por otra parte, mientras que el descenso de la participación del Perú es continuo, pero irregular, por las razones antes comentadas, en el caso de los Estados Unidos este se inicia desde los años ochenta, pero es más claro a partir del último quinquenio de la década de 1990. En el caso del Reino Unido, la caída de la participación salarial en el producto comienza en los años setenta. El punto máximo de la participación de la masa salarial en el PIB del Perú se registró en los años sesenta, mientras que en los Estados Unidos y el Reino Unido fue en la década de 1970.

\section{Gráfico 4}

Perú, Estados Unidos y Reino Unido: tendencia de la participación salarial en el PIB (En porcentajes del PIB)

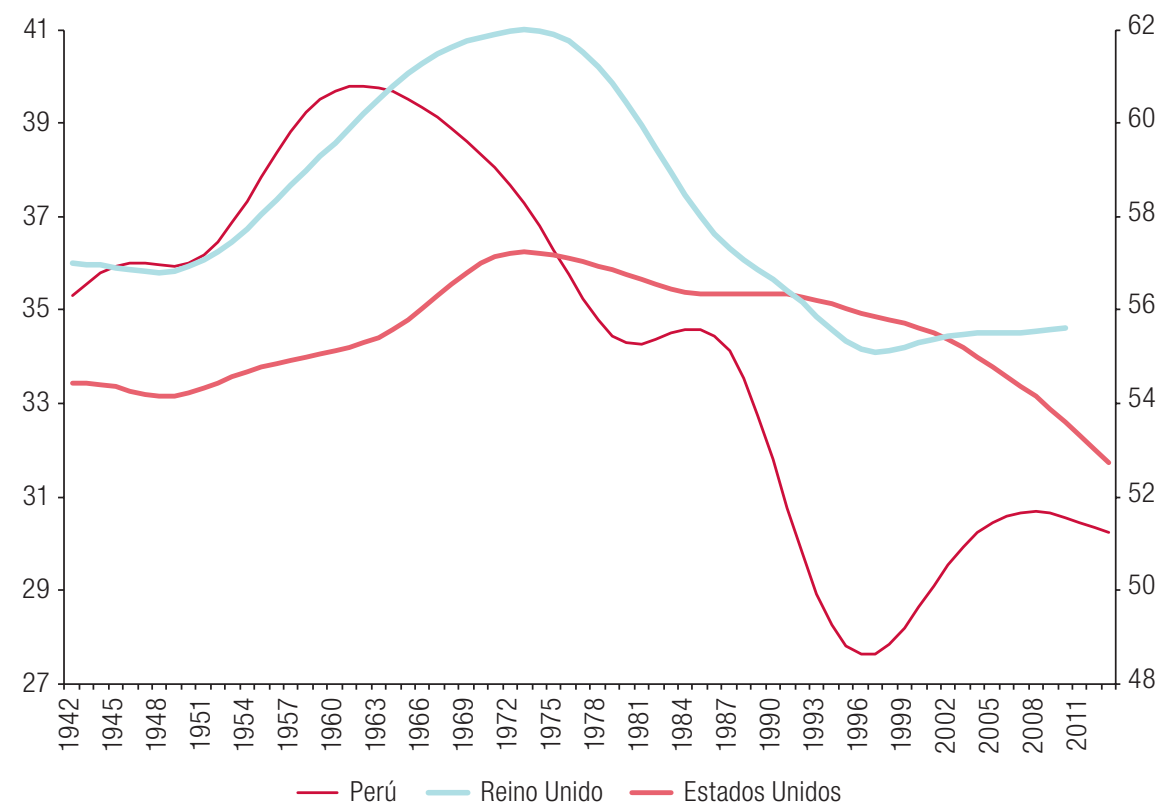

Fuente: Elaboración propia, sobre la base de Banco Central de Reserva del Perú (BCRP); Instituto Nacional de Estadística e Informática (INEI); Oficina de Análisis Económicos; y T. Piketty y G. Zucman, "Capital is back: wealth-income rations in rich countries, 1700-2010", Working Paper, París, Paris School of Economics, 2013.

\section{Relación entre participación salarial y crecimiento económico}

En el gráfico 5 se muestra la trayectoria por décadas de la masa salarial sobre el PIB y el crecimiento económico del Perú y de América Latina para el período que se analiza. Los resultados se obtienen a partir de la información promedio de la participación salarial y la media geométrica del crecimiento del PIB del país y la región. Es útil para evaluar si se transita de una situación menos favorable a otra más ideal cuando la participación de la masa salarial se incrementa al tiempo que aumenta el crecimiento económico, o si se pasa de una situación mejor a otra peor cuando ambas variables tienen valores menores que los iniciales o cuando hay una compensación si se presenta un menor crecimiento 
económico mientras se eleva la participación de la masa salarial en el PIB. Por otra parte, esta relación también sirve para determinar gráficamente los períodos en que la economía latinoamericana es dirigida por los salarios (cuando la relación es directa o positiva) y cuando es dirigida por las ganancias (cuando esta relación es negativa).

Gráfico 5

Perú y América Latina: trayectoria de la participación salarial en el PIB y el crecimiento económico, 1950-2013

(En porcentajes)

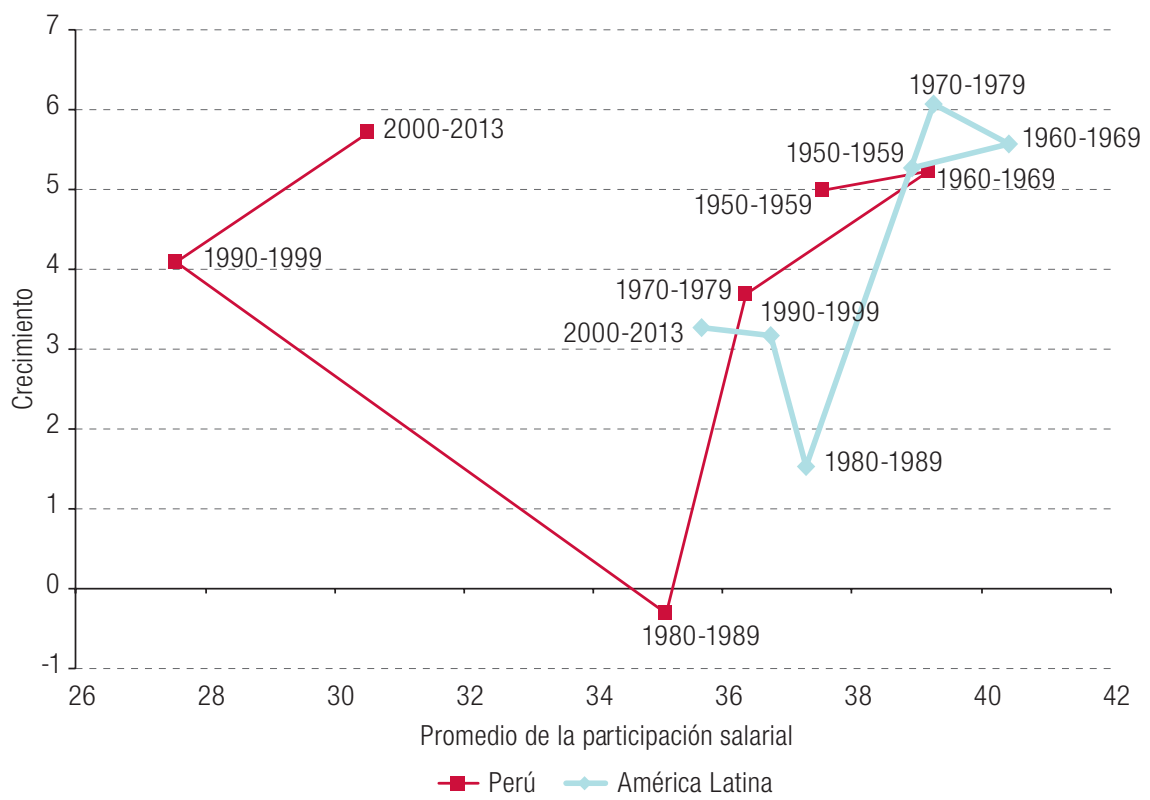

Fuente: Elaboración propia, sobre la base de Banco Central de Reserva del Perú (BCRP); Instituto Nacional de Estadística e Informática (INEI); Comisión Económica para América Latina y el Caribe (CEPAL); y G. Alarco, "Participación salarial y crecimiento económico en América Latina 1950-2013", Revista CEPAL, № 113 (LC/G.2614-P), Santiago, Comisión Económica para América Latina y el Caribe (CEPAL), 2014.

Es interesante anotar que la relación de la economía peruana se mueve en un rango claramente mayor al de toda América Latina, lo que denota la extrema variabilidad del Perú. Por otra parte, una conclusión general para América Latina es que entre 1950 y 2013 la combinación conjunta de la estructura distributiva y la tasa de crecimiento económico no ha sido claramente ventajosa. Se ha retrocedido en términos de la participación salarial en el producto y también en la tasa de crecimiento del producto. En el caso del Perú hay un retroceso en la estructura distributiva, pero solo una ligera mejora en el ritmo de crecimiento económico. Otra cuestión relevante en el caso peruano es que solo en la década de 1990 parece predominar una economía dirigida por las ganancias (por la pendiente negativa), mientras que en el resto del período -incluido lo que va del siglo XXI- predomina una economía dirigida por los salarios. El crecimiento económico tuvo un alto costo en términos distributivos. En América Latina esto ocurre tanto en los años setenta como en los años noventa.

\section{Modelo y régimen de crecimiento económico en el Perú}

El modelo básico estructural para evaluar el régimen de crecimiento es una variante del creado por Naastepad y Storm (2007). Se pretende evaluar cuál sería el efecto de un cambio en el producto $(X)$ 
ante un cambio en la participación de la masa salarial y del ingreso de los independientes en el PIB ${ }^{6}$. En la ecuación (1) se describe al PIB como la suma, a precios constantes, de la identidad tradicional por el lado del gasto: consumo privado (C), inversión privada (I), consumo e inversión pública (G), exportaciones de bienes y servicios (E) e importaciones de bienes y servicios (M). En la ecuación (2) se detalla el consumo privado como la multiplicación de la propensión a consumir de los asalariados e independientes $\left(\delta_{w}\right)$ por la masa salarial ajustada más la suma de la propensión a consumir de los propietarios $\left(\delta_{\pi}\right)$ por las ganancias (diferencia del PIB menos la masa salarial). La inversión privada se muestra en la ecuación (3) como una función lineal de las ganancias y del producto (efecto acelerador de la inversión), siendo $\theta_{0}$ y $\theta_{1}$ los parámetros de dicha variable, esperando que ambos sean mayores de cero. Las exportaciones de bienes y servicios de la ecuación (4) son una función lineal de la demanda mundial (Z) y dependen de las ganancias o del PIB menos la masa salarial, siendo $\varepsilon_{0}$ y $\varepsilon_{1}$ sus parámetros respectivos. En la ecuación (5) se detallan las importaciones de bienes y servicios, que son una función lineal de la propensión a importar $\left(\alpha_{1}\right)$ por el producto. Todas las funciones, excepto el consumo privado, tienen un parámetro constante.

$$
\begin{gathered}
X=C+I+G+E-M \\
C=\delta_{w} W+\delta_{\pi}(X-W) \\
I=f(\pi, X)=A_{I}+\theta_{0 \pi}+\theta_{1} X \\
E=g(Z, \pi)=A_{E}+\varepsilon_{0} Z+\varepsilon_{1} \pi \\
M=\alpha_{0}+\alpha_{2} X
\end{gathered}
$$

A partir de estas ecuaciones se debe evaluar el impacto de una modificación de la masa salarial ajustada y del ingreso de los independientes en el producto. Al respecto, en la ecuación (6) se expresa la elasticidad del producto respecto de la masa salarial ajustada $\left(E_{X W}\right)$ a partir de incorporar la ecuación (2) en la ecuación (1), derivar el producto respecto de la masa salarial ajustada en el PIB, suponer que el gasto público (corriente y de inversión pública) es insensible a las variaciones de la participación de la masa salarial y definir tanto la elasticidad del consumo privado respecto de la masa salarial ajustada en el PIB $\left(E_{C W}\right)$, como la elasticidad de la inversión privada respecto de la masa salarial ajustada en el PIB $\left(E_{I W}\right)$ y la elasticidad de las exportaciones de bienes y servicios respecto de la masa salarial ajustada en el PIB $\left(E_{E W}\right)$.

$$
E_{X W}=(C / X) E_{C W}+(I / X) E_{I W}+(E / X) E_{E W}-\alpha E_{X W}
$$

En las ecuaciones (7), (8), (9) y (10) se presentan las respectivas $E_{C W}, E_{I W}, E_{E W}$ y $E_{M W}$ como resultado de derivar las ecuaciones (2), (3), (4) y (5) respecto del cambio en la masa salarial ajustada. En la ecuación (11) se muestra el resultado final de la elasticidad del producto ante variaciones en la masa salarial ajustada considerando como base las ecuaciones (6), (7), (8), (9) y (10). Esta forma reducida considera tanto el multiplicador del gasto donde se encuentra la propensión a consumir de los propietarios de los medios de producción, como los parámetros de la inversión privada, el parámetro de las exportaciones respecto de las ganancias y la propensión a importar de la economía. En el numerador se ubican la diferencia de las propensiones a consumir de los asalariados y de los propietarios, la reacción de la inversión privada respecto de la ganancia y la reacción de las

\footnotetext{
6 En adelante, se denominará como "masa salarial ajustada" debido a que la propensión a consumir de los asalariados y los independientes es más cercana que la de los propietarios.
} 
exportaciones respecto de las ganancias multiplicadas por la participación de la masa salarial ajustada en el PIB. Si el resultado final $E_{X W}>0$ predomina el régimen de crecimiento basado en salarios, mientras que si $E_{X W}<0$ predominaría el régimen basado en ganancias.

$$
\begin{gathered}
E_{C W}(C / X)=\left(\delta_{w}-\delta_{\pi}\right)(W / X)+\delta_{\pi} E_{X W} \\
E_{I W}(I / X)=\left(\theta_{0}+\theta_{1}\right) E_{X W}-\theta_{0}(W / X) \\
E_{E W}(E / X)=\varepsilon_{1} E_{X W}-\varepsilon_{1}(W / X) \\
E_{M W}(M / X)=\alpha_{1} E_{X W} \\
E_{X W}=\left[1 /\left(1-\delta_{\pi}-\left(\theta_{0}+\theta_{1}\right)-\varepsilon_{1}+\alpha_{1}\right)\right]\left[\left(\delta_{w}-\delta_{\pi}\right)-\theta_{0}-\varepsilon_{1}\right](W / X)
\end{gathered}
$$

La información para aplicar el modelo de régimen de crecimiento es del BCRP, el INEI y el Ministerio de Hacienda y Comercio (1959). En el caso de la información internacional se utiliza la correspondiente a las Naciones Unidas y a Maddison (2001) para completar los períodos iniciales del PIB mundial. Las participaciones del consumo privado, la inversión privada y las exportaciones respecto del PIB corresponden al valor promedio del período 1942-2013.

El procedimiento para determinar el régimen de crecimiento económico de la economía peruana consta de tres etapas. En la primera etapa se estiman simultáneamente todos los parámetros de las funciones de consumo privado, inversión privada, exportaciones e importaciones de bienes y servicios, considerando las variables señaladas en las ecuaciones (2), (3), (4) y (5) 7 . La segunda etapa consiste en calcular la elasticidad del consumo privado respecto de la participación de la masa salarial ajustada en el PIB (ECW), la elasticidad de la inversión privada respecto de la participación de la masa salarial ajustada en el PIB $\left(E_{I W}\right)$ y la elasticidad de las exportaciones de bienes y servicios respecto de la participación de la masa salarial ajustada en el PIB $\left(E_{I W}\right)$ de acuerdo con las fórmulas descritas en las ecuaciones (9), (10) y (11). Por último, estos resultados se reemplazan en la ecuación (10) relativa a la elasticidad del producto respecto de la participación de la masa salarial ajustada en el PIB $\left(E_{X W}\right)$ para evaluar si $E_{X W}>0$, donde tendríamos un régimen de crecimiento económico basado en salarios, o si $E_{X W}<0$, donde correspondería uno basado en ganancias.

Los resultados para los diferentes parámetros se han estimado mediante dos técnicas econométricas de ecuaciones simultáneas: los mínimos cuadrados en tres etapas (MC3E) y el método generalizado de momentos (MGM) utilizando el software Eviews, cuyos resultados se muestran en el cuadro 2. En ambos casos, el número de observaciones consideradas es de 72 años para cada variable dependiente e independiente. A las consideradas al inicio en las ecuaciones (2), (3), (4) y (5) no se han agregado otras variables de control o instrumento, variables desfasadas, ni variables ficticias para mantener la lógica integral del modelo, la comparabilidad de sus resultados y la facilidad para obtener las elasticidades correspondientes.

Los resultados obtenidos para las diferentes ecuaciones y parámetros son razonables y se destaca una mayor superioridad en los ajustes cuando se aplica el método MC3E respecto del MGM. Con el primer método, la bondad de ajuste de las cuatro ecuaciones fluctúa entre 0,90 y 0,99, mientras que con el MGM es 0,54 en el caso de la inversión privada y entre 0,7 y 0,98 para el resto de las ecuaciones. En la estimación a través de MC3E todos los parámetros son significativamente diferentes de cero al 99\% de confianza a excepción del parámetro que vincula la inversión privada con las ganancias. En el caso del MGM hay problemas en los parámetros de la constante tanto

7 Todas las variables se expresan en términos reales. 
de la inversión privada como de las exportaciones. El grado de significación del parámetro de la inversión privada respecto de las ganancias y de las exportaciones con relación a las ganancias es significativamente diferente de cero al 95\% de confianza.

\section{Cuadro 2}

Perú: principales funciones explicativas del consumo privado, la inversión privada y las exportaciones, 1942-2013

\begin{tabular}{|c|c|c|c|c|c|c|c|}
\hline \multirow[b]{2}{*}{ Ecuación } & \multirow{2}{*}{$\begin{array}{l}\text { Método de } \\
\text { estimación }\end{array}$} & \multicolumn{5}{|c|}{ Variables independientes } & \multirow[b]{2}{*}{$\mathrm{R}^{2}$} \\
\hline & & $\begin{array}{l}\text { Masa salarial } \\
\text { ajustada }\end{array}$ & Ganancias & $\mathrm{PIB}$ & $\begin{array}{c}\text { Demanda } \\
\text { mundial }\end{array}$ & Constante & \\
\hline \multirow{4}{*}{ Consumo privado } & \multirow{2}{*}{ MC3E } & 0,9502 & 0,4366 & & & & \multirow{2}{*}{0,9894} \\
\hline & & $(37,4587)^{\star \star \star}$ & $(9,8423)^{\star \star \star}$ & & & & \\
\hline & \multirow{2}{*}{ MGM } & 0,8683 & 0,6764 & & & & \multirow{2}{*}{0,9790} \\
\hline & & $(35,0889)^{\star \star \star}$ & $(14,3631)^{\star \star \star}$ & & & & \\
\hline \multirow{4}{*}{ Inversión privada } & \multirow{2}{*}{ MC3E } & & 0,0820 & 0,1636 & & $-7,14 \mathrm{E}+09$ & \multirow{2}{*}{0,9005} \\
\hline & & & $\left(1,5290^{\prime}\right)$ & $(8,2325)^{\star \star \star}$ & & $(-4,9842)^{\star \star \star}$ & \\
\hline & \multirow{2}{*}{ MGM } & & $-0,1461$ & 0,1409 & & $5,66 \mathrm{E}+08$ & \multirow{2}{*}{0,5386} \\
\hline & & & $(7,1207)^{\star \star \star}$ & $(-2,2521)^{\star}$ & & $\left(0,6961^{\prime}\right)$ & \\
\hline \multirow{4}{*}{$\begin{array}{l}\text { Exportaciones de } \\
\text { bienes y servicios }\end{array}$} & \multirow{2}{*}{ MC3E } & & 0,2891 & & 0,0012 & $-6,22 E+09$ & \multirow{2}{*}{0,9108} \\
\hline & & & $(6,5644)^{\star \star \star}$ & & $(14,1005)^{\star \star}$ & $(-4,9152)^{\star \star *}$ & \\
\hline & \multirow{2}{*}{ MGM } & & 0,0743 & & 0,0011 & $-1,44 \mathrm{E}+09$ & \multirow{2}{*}{0,7486} \\
\hline & & & $(2,0605)^{\star \star}$ & & $(17,0941)^{\star \star}$ & $(-1,6829)$ & \\
\hline \multirow{4}{*}{$\begin{array}{l}\text { Importaciones de } \\
\text { bienes y servicios }\end{array}$} & \multirow{2}{*}{ MC3E } & & & 0,2558 & & $-1,12 \mathrm{E}+10$ & \multirow{2}{*}{0,9290} \\
\hline & & & & $(30,5657)^{\star \star \star}$ & & $(-7,3075)^{\star \star \star}$ & \\
\hline & \multirow{2}{*}{ MGM } & & & 0,1511 & & $-1,66 \mathrm{E}+09$ & \multirow{2}{*}{0,7076} \\
\hline & & & & $(16,8812)^{\star \star \star}$ & & $(-2,2626)^{\star \star \star}$ & \\
\hline
\end{tabular}

Fuente: Elaboración propia, sobre la base de Banco Mundial; Banco Central de Reserva del Perú (BCRP); Instituto Nacional de Estadística e Informática (INEI); Naciones Unidas; Ministerio de Hacienda y Comercio; y A. Maddison, The World Economy. A Millennial Perspective, París, Organización de Cooperación y Desarrollo Económicos (OCDE), 2001.

* Estimado significativamente diferente de cero al 95\%.

** Estimado significativamente diferente de cero al $99 \%$.

*** Estimado significativamente diferente de cero al 99,5\%.

En ambos métodos de estimación, las propensiones a consumir de los asalariados son superiores a las correspondientes a los propietarios de los medios de producción. Mediante la técnica de MC3E estas corresponden a 0,95 y 0,44, respectivamente, en tanto que con el MGM tienen valores de 0,87 y 0,68, respectivamente. Otros parámetros interesantes de mencionar son el acelerador del PIB en la inversión privada, que tiene un valor de 0,16 mediante el método MC3E y de 0,14 con el MGM. Llama la atención la diferencia de valor y signo del parámetro que vincula la inversión privada con las ganancias: en el caso del MC3E es de 0,08, mientras que mediante el MGM es de -0,15. El parámetro de las exportaciones respecto de la demanda mundial es pequeño por la magnitud de los números de la serie estadística de esta variable: con ambos métodos de estimación tiene un valor de 0,001. Por último, la propensión a importar de la economía es de 0,26 con el MC3E, mientras que con el MGM llega a 0,16. Los valores de los parámetros constantes son elevados.

En el cuadro 3 se muestran los resultados de los diferentes componentes del consumo privado, de la inversión privada, de las exportaciones, de las importaciones y la elasticidad del PIB ante cambios de la masa salarial en el PIB de la ecuación (10). Se presentan los resultados para el período 19422013 mediante los métodos MC3E y MGM. En todos los casos se considera el efecto del cambio porcentual en la masa salarial ajustada sobre cada componente de la demanda en el mismo período de tiempo. 
Cuadro 3

Perú: componentes de la demanda y elasticidad de la participación de la masa salarial ajustada respecto del PIB, 1942-2013

\begin{tabular}{lcc}
\hline Elasticidades & Estimación con MC3E & Estimación con GMM \\
\hline Elasticidad del PIB respecto de masa salarial & 0,3601 & 0,3822 \\
\hline Componente del consumo privado & 0,6776 & 0,5481 \\
\hline Componente de la inversión privada & 0,4658 & 0,6631 \\
\hline Componente de las exportaciones & $-0,3387$ & $-0,0786$ \\
\hline Componente de las importaciones & 0,6018 & 0,3774 \\
\hline Multiplicador & 2,7286 & 2,4654 \\
\hline
\end{tabular}

Fuente: Elaboración propia, sobre la base de Banco Mundial; Banco Central de Reserva del Perú (BCRP); Instituto Nacional de Estadística e Informática (INEI); Naciones Unidas; Ministerio de Hacienda y Comercio; y A. Maddison, The World Economy. A Millennial Perspective, París, Organización de Cooperación y Desarrollo Económicos (OCDE), 2001.

En todos los casos, el componente del consumo privado tiene un valor positivo por la diferencia entre la propensión a consumir de los asalariados e independientes y la de los propietarios de los medios de producción. De esta forma, un incremento de la masa salarial ajustada eleva el consumo privado. Asimismo, el componente de la inversión privada se incrementa cuando aumenta la masa salarial, lo que da cuenta de una naturaleza procíclica: a mayor crecimiento de la masa salarial, se produciría una mayor inversión privada. Sin embargo, el componente de las exportaciones respecto de la masa salarial tiene un valor negativo al afectar las ganancias (y por consiguiente su rentabilidad) ${ }^{8}$. Por otra parte, el aumento de la masa salarial eleva las importaciones reduciendo el PIB. El resultado final de la elasticidad del producto ante un incremento porcentual de la masa salarial incorpora un multiplicador de entre 2,7 y 2,5 y un valor final de entre 0,36 y 0,38 para el MC3E y el MGM, respectivamente. La elasticidad del PIB ante cambios en la masa salarial ajustada es positiva, pero inelástica. El régimen de crecimiento económico para el período 1942-2013 estaría basado en salarios. Las políticas distributivas a favor de la masa salarial serían positivas a nivel de la actividad económica.

\section{Conclusiones}

Si bien la problemática de la distribución factorial del ingreso y el crecimiento económico era un tema importante para los economistas clásicos, desapareció desde la escuela neoclásica. Los diferentes grupos sociales perdieron importancia, fueron sustituidos por la división entre consumidores y productores, y dominó la ley de Say, según la cual la oferta siempre crea su propia demanda. Recién con Keynes, con la recomendación de aplicar impuestos a los ingresos y las herencias en épocas de crisis por insuficiencia de la demanda, la estructura de distribución del ingreso vuelve a tener un papel mediante el impacto en la propensión a consumir y después en el multiplicador del gasto, que son útiles para determinar la demanda y el nivel de actividad económica.

Kalecki transparenta la división de la sociedad en grupos sociales, otorgándole a cada uno funciones y comportamientos específicos, tanto a nivel de la empresa como de la industria y la macroeconomía en general. La distribución del ingreso se va gestando desde el proceso de formación de precios, en el que intervienen los salarios, los insumos, el poder en el mercado de los propietarios de los medios de producción a través del grado de monopolio y otros factores y coeficientes técnicos. A nivel agregado, el grado de actividad económica depende de la participación de la masa salarial en el producto, de los diferentes componentes de la demanda interna y externa, y de otros elementos. La mejora de la participación salarial en el producto mejorará el nivel de demanda y producción.

\footnotetext{
8 Las estimaciones reflejan una vinculación positiva entre las exportaciones y las ganancias, pero no se debe olvidar que entre el $75 \%$ y el $80 \%$ de estas corresponden a exportaciones tradicionales que son intensivas en capital y que han crecido más a la par de lo que se elevaron los términos de intercambio externos, por lo que esta relación directa podría ser no causal.
} 
A partir de los trabajos de Boyer, Bhaduri y Marglin se abre el abanico de resultados posibles ante una variación de la masa salarial en el producto. Esto se perfecciona con Stockhammer y otros autores. La modificación de la masa salarial incide no solo en el consumo privado, como preveía Kalecki, sino también en la inversión privada y en las exportaciones netas. El resultado final por el lado de la demanda y el PIB dependerá de los valores de respuesta y el peso de cada uno de estos componentes. Obviamente, como en cualquier enfoque, surgen algunas observaciones sobre la metodología apropiada para evaluar estos efectos.

Un elemento clave para analizar la distribución factorial del ingreso y determinar el régimen de crecimiento económico del Perú es la construcción de las series estadísticas de sus diferentes componentes. Esto parecería sencillo, pero no lo es pues desde los años ochenta ya no se trata de un tema relevante. Hay problemas de agregación y en la continuidad de estas series. La estadística oficial de largo plazo solo presenta el PIB por el lado de la demanda y por sectores productivos, pero no por el lado del ingreso. La atención ahora se centra en la distribución personal del ingreso, olvidando, por el dominio de la perspectiva neoclásica, que el ingreso y la distribución dependen, en primera instancia, de la posición de las personas en el proceso productivo: asalariados, perceptores de ganancias o propietarios de los medios de producción e independientes (ingreso mixto). Aquí se presentan y comentan las series reconstruidas para estos tres componentes, distinguiendo del excedente bruto de explotación a las ganancias y los ingresos de los independientes. Se presentan las series estadísticas entre 1942 y 2013. Este es un ejercicio que podría aplicarse para otras economías de la región.

La tendencia no lineal de la participación de la masa salarial en el producto del Perú muestra una forma sinusoidal decreciente. Efectivamente, hay ciclos con un punto máximo en los años sesenta que comienza a decrecer desde mediados de la década de 1970 (desequilibrios internos de la primera y segunda fase del gobierno militar y choque petrolero), y con una caída pronunciada a finales de los años ochenta y hasta mediados de los años noventa (nuevo modelo hacia afuera). De ahí en adelante hay una recuperación y se registra un estancamiento hacia el final del período. En el caso de la participación de los ingresos mixtos, como resultado del proceso de urbanización y de deterioro de los precios agrícolas, la tendencia es descendente, con un pequeño ciclo expansivo hacia finales del siglo XX e inicios del siglo XXI. Por otra parte, la tendencia de la participación de las ganancias es creciente, con ciclos expansivos a inicios de los años cincuenta, el segundo quinquenio de los años setenta, la década de 1990 y lo que va del siglo XXI. En gran parte, estos ciclos expansivos se explican por la mejora de los precios de las materias primas que se exportan.

Tanto el nivel de la participación salarial en el PIB como la tendencia descendente de la participación de la masa salarial en el PIB del Perú son más pronunciados que los de América Latina en su conjunto. Asimismo, en la región la caída se focaliza en los años ochenta y noventa, y la recuperación recién se produce en el siglo XXI, sobre todo como resultado de las políticas salariales expansivas de la Argentina y el Brasil. Además, la región comparte una trayectoria similar a la del Reino Unido, donde la caída se inicia en los años ochenta. Lo mismo ocurre en los Estados Unidos, pero aquí el descenso más pronunciado se observa desde la década de 1990. Ello se debe a que en los años ochenta la disminución de los sueldos y salarios se vio parcialmente compensada con el aumento de otras contribuciones empresariales a los trabajadores relativas a la salud, los seguros y los fondos de pensiones.

La participación de la masa salarial y de las ganancias en el PIB ya no solo depende de la política salarial, el grado de monopolio o el margen de ganancia, ni del peso de los sectores extractivos en la economía, sino que, en el caso de una economía como la peruana, exportadora de productos mineros y otras materias primas, dependerá de los términos de intercambio externos. Los mayores precios internacionales de estos bienes contribuyen al aumento de la participación de las ganancias en el PIB y por diferencia a la caída de participación de la masa salarial. Por otra parte, el aumento del 
salario mínimo real incrementa la participación de la masa salarial. Asimismo, tanto la elevación de los precios del petróleo como el aumento de las tasas de interés activas reducen la participación de la masa salarial en el PIB ${ }^{9}$. Es interesante anotar que, para la mayor parte del período analizado, una baja inflación no es negativa respecto de la participación de la masa salarial en el producto, mientras que, si la inflación es alta o hay un proceso hiperinflacionario, el resultado sí es sensiblemente negativo. Como resulta obvio, las políticas de ajuste y estabilización convencionales también son negativas respecto de la cuota salarial en el producto.

La trayectoria general en cuanto a la participación de los salarios en el PIB y la tasa de crecimiento económica no ha sido positiva ni para el Perú ni para América Latina. Entre 1950 y 2013 se ha reducido la participación salarial y no se ha presentado una mejora significativa en la tasa de crecimiento económico promedio. Al respecto, la situación es más negativa para América Latina que para el Perú, aunque es claro que la variabilidad es mayor en el caso de esta economía particular que en el promedio regional. Por otra parte, cuando se realiza un análisis por décadas resulta evidente que ambas variables se mueven en una relación directa y positiva que, de manera preliminar, implicaría un régimen de crecimiento basado en salarios para casi todo el período que se analiza. Solo en los años noventa predominaría un régimen basado en ganancias ${ }^{10}$.

A partir de la lógica del modelo de Naastepad y Storm (2007), se diseñó un sistema de cinco ecuaciones simultáneas lineales, útiles para determinar el régimen de crecimiento económico del Perú. Se realizaron estimaciones integrales para el período 1942-2013 (72 observaciones) utilizando tanto el método de MC3E como el MGM. En todos los casos, los incrementos de la masa salarial ajustada en el PIB son positivos respecto de la demanda y el nivel de actividad económica. En la práctica, sin embargo, el incremento de la masa salarial sobre las exportaciones es negativo, lo que neutraliza parcialmente el efecto positivo sobre el consumo privado. No obstante, en ambas estimaciones, la inversión privada aumenta ante el incremento de la masa salarial. El resultado conjunto de considerar todos los efectos por el lado de la demanda es que el PIB aumenta en la medida en que se eleva la masa salarial. La elasticidad del PIB respecto de la masa salarial fluctúa entre 0,36 y 0,38. Un aumento de la masa salarial del $1 \%$ eleva el PIB entre el 0,36\% y el 0,38\%. Con estos resultados predominaría el régimen de crecimiento basado en salarios.

Un régimen de crecimiento basado en los salarios requeriría de políticas redistributivas a favor de este componente del ingreso nacional. Sin embargo, debe anotarse que también hay límites a estas políticas debido a los posibles efectos negativos sobre los precios y la balanza de pagos, además de que en casos extremos podrían desalentar la inversión privada. La determinación de esos umbrales o límites es un tema complejo, ya que depende de elementos no solo económicos, sino también sociopolíticos e institucionales. Por otra parte, en este estudio, a pesar de las salvedades metodológicas señaladas, se ha supuesto que la econometría es el instrumento razonable para determinar el régimen de crecimiento económico. En realidad, el cambio de un régimen a otro es un proceso continuo y enrevesado que se da en el tiempo. La crisis en el modelo de industrialización dirigida desde el Estado, las políticas de ajuste y estabilización, y después las reformas estructurales neoliberales pusieron en jaque el modelo de crecimiento basado en los salarios. Ahora, con la crisis del sector externo que afecta a muchas economías, principalmente exportadoras de materias primas, los nuevos escenarios negativos que se pueden generar a partir del Brexit y el triunfo de Trump en los Estados Unidos, se alentaría el camino para diseñar e implantar políticas asociadas a un régimen de crecimiento basado en salarios. El detalle y la magnitud específica de las políticas distributivas prosalarios e ingreso de los independientes que coadyuven al crecimiento económico, pero que minimicen los efectos negativos en otras esferas macroeconómicas, rebasan los alcances de este documento.

\footnotetext{
9 Este efecto es considerado en el modelo macroeconómico de corto plazo desarrollado por Dutt y Ros (2007).

${ }^{10}$ Esto también ocurriría en los años setenta en el caso de América Latina.
} 


\section{Bibliografía}

Abeles, M., V. Amarante y D. Vega (2014), "Participación del ingreso laboral en el ingreso total en América Latina, 1990-2010", Revista CEPAL, № 114 (LC/G.2629-P), Santiago, Comisión Económica para América Latina y el Caribe (CEPAL).

Alarco, G. (2016), "Distribución factorial del ingreso y regímenes de crecimiento en América Latina, 1950-2013”, Revista Internacional del Trabajo, vol. 135, № 1, Ginebra, Organización Internacional del Trabajo (OIT). (2014), "Participación salarial y crecimiento económico en América Latina, 1950-2011", Revista CEPAL, № 113 (LC/G.2614-P), Santiago, Comisión Económica para América Latina y el Caribe (CEPAL).

Banco Mundial (2014), "World Development Indicators" [en línea] http://databank.worldbank.org/ddp/home. do?Step $=1 \& i d=4$.

Bértola, L. y otros (2008), "Income distribution in the Latin American Southern Cone during the first globalization boom, ca: 1870-1920", Working Papers in Economic History, № 08-05, Madrid, Universidad Carlos III de Madrid.

Bhaduri, A. (2007), "On the dynamics of profit-led and wage-led growth", Cambridge Journal of Economics, vol. 32, No 1, Oxford University Press.

Bhaduri, A. y S. Marglin (1990), "Unemployment and the real wage: the economic basis for contesting political ideologies", Cambridge Journal of Economics, vol. 14, № 4, Oxford, Oxford University Press.

Bowles, S. y R. Boyer (1988), "Labor discipline and aggregate demand: a macroeconomic model", The American Economic Review, vol. 78, № 2, Nashville, Tennessee, American Economic Association.

Boyer, R. (1988a), "Formalizing growth regimes within a regulation approach. A method for assessing the economic consequences of technological change", Technical Change and Economic Theory, G. Dosi y otros (eds.), Londres, Pinter Publishers.

(1988b), "Technical change and the theory of 'regulation'”, Technical Change and Economic Theory, G. Dosi y otros (eds.), Londres, Pinter Publishers.

Castillo, C. (2015), "Distribución factorial del ingreso en el Perú 1942-2013", tesis, Lima, Universidad del Pacífico [en línea] http://repositorio.up.edu.pe/bitstream/handle/11354/1139/C\%C3\%A9sar_Tesis_maestria_2015. pdf? sequence=1\&isAllowed $=\mathrm{y}$.

CEPAL (Comisión Económica para América Latina y el Caribe) (2013), "Estadísticas e indicadores" [en línea] http://estadisticas.cepal.org/cepalstat/WEB_CEPALSTAT/estadisticasIndicadores.asp?idioma=e.

CEPAL/OIT (Comisión Económica para América Latina y el Caribe/Organización Internacional del Trabajo) (2012), "Productividad laboral y distribución", Coyuntura Laboral en América Latina y el Caribe, № 6, Santiago.

Cingano, F. (2014), "Trends in income inequality and its impact on economic growth", OECD Social, Employment and Migration Working Papers, № 163, París, Organización de Cooperación y Desarrollo Económicos (OCDE).

Dutt, A. K. y J. Ros (2007), "Aggregate demand shocks and economic growth", Structural Change and Economic Dynamics, vol. 18, № 1, Amsterdam, Elsevier.

Figueroa, A. (2010), "Crecimiento versus calidad de vida", Rutas hacia un Perú mejor. Qué hacer y cómo lograrlo, G. Alarco (ed.), Lima, Centro de Negocios (CENTRUM) de la Pontificia Universidad Católica del Perú/Aguilar.

Fitzgerald, V. (2009), "La distribución de ingresos y rentas en América Latina durante el siglo XX: un estudio inicial", Cuadernos Económicos de ICE, № 78, Madrid.

Frankema, E. (2009), "Reconstructing labour income shares in Argentina, Brazil and Mexico, 1870-2000", Documento de Trabajo, Utrecht, Universidad de Utrecht.

García, N. (2013), "Fast economic growth and income distribution (Peru 1990-2010)", Economie Appliquée, № 1 [en línea] http://www.itf.org.ar/pdf/documentos/89_2013.pdf.

Kaldor, N. (1955), "Alternative theories of distribution", The Review of Economic Studies, vol. 23, № 2, Oxford University Press.

Kalecki, M. (1956), Teoría de la dinámica económica: ensayos sobre los movimientos cíclicos y a largo plazo de la economía capitalista, Ciudad de México, Fondo de Cultura Económica.

Keynes, J. M. (1943), Teoría general del empleo, el interés y el dinero, Ciudad de México, Fondo de Cultura Económica.

Kumhof, M. y R. Rancière (2010), "Inequality, leverage and crises", IMF Working Paper, N WP/10/268, Washington, D.C., Fondo Monetario Internacional (FMI).

Lakner, C. y B. Milanovic (2015), "La distribución global del ingreso de la caída del Muro de Berlín a la Gran Recesión”, Revista de Economía Institucional, vol. 17, № 32, Bogotá, Universidad Externado de Colombia. 
Lindenboim, J. (2008), "Distribución funcional del ingreso, un tema olvidado que reclama atención", Problemas del Desarrollo, vol. 39, № 153, Ciudad de México, Universidad Nacional Autónoma de México.

Maddison, A. (2001), The World Economy. A Millennial Perspective, París, Organización de Cooperación y Desarrollo Económicos (OCDE).

Marshall, A. (1957), Principios de economía. Un tratado de introducción, Madrid, Aguilar.

Ministerio de Hacienda y Comercio (1959), Anuario Estadístico del Perú 1956-1957, Lima, Dirección Nacional de Estadística y Censos.

Naastepad, C. W. M. y S. Storm (2007), "OECD demand regimes (1960-2000)", Journal of Post Keynesian Economics, vol. 29, № 2, Taylor \& Francis.

Neira Barría, V. (2010), "Distribución factorial del ingreso en América Latina, 1950-2000: nuevas series a partir de las cuentas nacionales", Documento de Trabajo, Barcelona, Universidad Pompeu Fabra.

Nikiforos, M. (2014), "Distribution-led growth in the long run", Documento de Trabajo, № 814, Nueva York, Levy Economics Institute of Bard College.

OIT (Organización Internacional del Trabajo) (2012), Panorama Laboral 2012. América Latina y el Caribe, Lima, Oficina Regional de la OIT para América Latina y el Caribe.

- (2011), "Hacia una recuperación sostenible: por una política de crecimiento basada en los salarios", Boletín Internacional de Investigación Sindical, vol. 3, Nㅜㄹ, Ginebra.

Onaran, Ö. y G. Galanis (2012), "Is aggregate demand wage-led or profit-led? National and global effects", Conditions of Work and Employment Series, № 40, Ginebra, Organización Internacional del Trabajo (OIT).

Onaran, Ö., E. Stockhammer y L. Grafl (2011), "Financialisation, income distribution and aggregate demand in the USA", Cambridge Journal of Economics, vol. 35, No 4, Oxford University Press.

(2009), "The finance-dominated growth regime, distribution, and aggregate demand in the US", Department of Economics Working Paper, № 126, Viena, Vienna University of Economics and Business.

Ostry, J., A. Berg y G. Tsangarides (2014), "Redistribution, inequality, and growth", IMF Staff Discussion Note, $N^{\circ}$ SDN/14/02, Washington, D.C., Fondo Monetario Internacional (FMI).

Oxfam (2014), Iguales: acabemos con la desigualdad extrema. Es hora de cambiar las reglas [en línea] http:// www.oxfamintermon.org/sites/default/files/documentos/files/InformelGUALES_AcabemosAcabemosConla Desigualda.pdf.

Palley, T. (2014), "Rethinking wage vs. profit-led growth theory with implications for policy analysis", IMK Working Paper, № 141, Düsseldorf, Macroeconomic Policy Institute.

Pedagua, L. E. (2009), "Alternativas metodológicas para el empalme estadístico de series temporales: caso Venezuela 1950-2005", Temas de Coyuntura, № 59, julio.

Piketty, T. (2014), El capital en el siglo XXI, Ciudad de México, Fondo de Cultura Económica.

Piketty, T. y G. Zucman (2013), "Capital is back: wealth-income rations in rich countries, 1700-2010", Working Paper, París, Paris School of Economics.

Quesnay, F. (1980). “La 'tercera edición' del ‘Tableau Économique'”, El Tableau Économique de Quesnay, M. Kuczynski y R. L. Meek (eds.), Ciudad de México, Fondo de Cultura Económica.

Ricardo, D. (1973), Principios de economía política y de tributación, Ciudad de México, Fondo de Cultura Económica.

Seminario, B. (2015), El desarrollo de la economía peruana en la era moderna. Precios, población, demanda y producción desde 1700, Lima, Universidad del Pacífico.

Smith, A. (2010), Investigación sobre la naturaleza y causas de la riqueza de las naciones, Ciudad de México, Fondo de Cultura Económica.

Stiglitz, J. (2015), La gran brecha. Qué hacer con las sociedades desiguales, Barcelona, Taurus.

Stockhammer, E. (2011), "Crecimiento basado en los salarios: introducción", Boletín Internacional de Investigación Sindical, vol. 3, № 2, Ginebra, Organización Internacional del Trabajo (OIT).

Stockhammer, E. y S. Ederer (2007), "Demand effects of the falling wage share in Austria", Department of Economics Working Paper, № 106, Viena, Vienna University of Economics and Business.

Stockhammer, E., E. Hein y L. Grafl (2011), "Globalization and the effects of changes in functional income distribution on aggregate demand in Germany", International Review of Applied Economics, vol. 25, № 1 , Taylor \& Francis.

Stockhammer, E. y Ö. Onaran (2004), "Accumulation, distribution and employment: a structural VAR approach to a Kaleckian macro model", Structural Change and Economic Dynamics, vol. 15, № 4, Amsterdam, Elsevier.

Stockhammer, E., Ö. Onaran y S. Ederer (2009), "Functional income distribution and aggregate demand in the Euro area", Cambridge Journal of Economics, vol. 33, № 1, Oxford University Press. 